\title{
Expression of matrix metalloproteinase-9 in the neoplastic and interstitial inflammatory infiltrate cells in gastric cancer
}

\author{
Barbara Mroczko', Marta Lukaszewicz-Zając1, Katarzyna Guzińska-Ustymowicz², \\ Mariusz Gryko ${ }^{3}$, Jolanta Czyżewska ${ }^{4}$, Andrzej Kemona ${ }^{2}$, Bogusław Kędra ${ }^{3}$ \\ and Maciej Szmitkowski ${ }^{1}$
}

\author{
${ }^{1}$ Department of Biochemical Diagnostics, ${ }^{2}$ Department of General Pathomorphology, \\ ${ }^{3}$ Department of General Surgery and Gastroenterology, ${ }^{4}$ Department of Clinical Laboratory Diagnostics, \\ Medical University, Białystok, Poland
}

\begin{abstract}
Matrix metalloproteinases (MMPs) play an important role in the extracellular matrix degradation, that is an essential step in tumor invasion and metastases. The current study objective was to evaluate the expression of MMP-9 in the neoplastic and in the interstitial inflammatory infiltrate cells in gastric cancer (GC). Moreover, the relationship between expression of this enzyme and clinicopathological features of GC, such as TNM stage, the depth of tumor invasion, lymph node and distant metastases were assessed. The study comprised 54 patients with gastric cancer. Immunohistochemistry was used to determine the expression of MMP-9 in gastric cancer cells. The semi-quantitative scale was applied to evaluate the expression of metalloproteinase-9. Immunohistochemical testing revealed a positive reaction of MMP-9 in $98 \%$ of all cancer tissue specimens and in $93 \%$ of inflammatory cells. The expression of MMP-9 in the neoplastic and inflammatory cells increased with more advance tumor stage, depth of tumor invasion and presence of lymph node as well as distant metastases. These findings indicate the significance of interstitial inflammatory infiltrate cells in the MMP-9 synthesis and the role of this enzyme in the invasiveness and metastatic potential of GC.
\end{abstract}

Key words: matrix metalloproteinases, gastric cancer, MMP-9 expression

\section{Introduction}

Gastric cancer is the fourth most common cancer and the second cause of cancer death in the world [1]. The prognosis for patients with gastric cancer remains poor, with an overall 5-year survival rate of $47 \%$ $60 \%$ [2]. It usually shows extensive local tumor invasion and early spread to metastasis sites [3]. The crucial step in the tumor development and metastasis is degradation of extracellular matrix (ECM) [3-5]. The invasion of cancer cells within the basement membrane depends on the activities of matrix metalloproteinases and their inhibitors (TIMPs) [3-5].

MMPs are a family of proteolytic enzymes associated with the tumor progression including invasion,

Correspondence: B. Mroczko, Dept. of Biochemical Diagnostics, Medical University, Białystok, Waszyngtona 15a, 15-269 Białystok, Poland; tel.: (+4885) 7468710, fax.: (+4885) 7468585, e-mail: mroczko@umwb.edu.pl migration, angiogenesis and metastasis $[3,4,6,7]$. Among the MMPs, especially matrix metalloproteinases 9 (MMP-9) and matrix metalloproteinases 2 (MMP-2) are connected with cancer metastasis, because of their ability to degrade type IV collagen [8]. However, it has been reported that the matrix-degrading activity of MMP-9 is nearly 25 times stronger than MMP-2 [9]. The high expression and involvement of MMP-9 in gastric cancer tissues have been determinated in several studies [10-14]. De Mingo et al [11] have shown that the expression of MMP-9 is related to a more aggressive phenotype of gastric cancer. The expression of MMP-9 in gastric cells correlated with tumor stage, depth of tumor invasion and presence of lymph node metastasis $[8,10,14]$. Gao et al [15] suggested that the expression of this enzyme was significantly higher in patients with metastasis and poorly differentiated carcinomas than in patients without metastasis and well/moderately differentiated tumors. The role of high MMP-9 expression in the invasion 
and metastasis was confirmed by other authors [16]. However, there is little known about MMP-9 expression in interstitial inflammatory infiltrate cells of GC.

It was shown that inflammatory cells and other non-neoplastic tumor stroma cells are linked to the processes of tumorigenesis [17-19]. These cells are also able to produce metalloproteinases to the peritumoral environment and to synthesize various cytokines enhancing expression of MMPs by both tumoral and stromal cells [20]. Gonzalez et al have shown the overexpression of MMP-9 in mononuclear inflammatory cells in breast cancer and its correlation with development of distant metastases [19]. Previously, we compared the intensity of MMP-9 expression in the neoplastic and interstitial inflammatory infiltrate cells in esophageal cancer and evaluated the expression of this enzyme in the different histopatological types of esophageal cancer [21].

According to our knowledge, this is the first study assessing the MMP-9 expression in the interstitial inflammatory infiltrate cells in GC tissues and their correlations with clinicopathological features of tumor. In the present study we analyzed the expression of MMP-9 in the neoplastic and inflammatory cells in GC. Additionally, we compared the intensity of MMP-9 expression in both types of cells with tumor stage, depth of tumor invasion (T factor) as well as lymph node ( $\mathrm{N}$ factor) and distant metastases (M factor) of GC.

\section{Materials and methods}

Patients. A total of fifty-four patients with gastric cancer (41 males and 13 females, aged 37-84 years) were included in this study. The material for immunohistochemical staining analysis was sampled in the course of surgery or gastroscopy. The tumors were staged in accordance with the TNM classification, proposed by the $5^{\text {th }}$ International Union Against Cancer (UICC) [22]. TNM staging of the tumor revealed 14 patients in stage I+II, 22 patients in stage III and 21 patients in stage IV. All GC patients were classified depending on depth of tumor invasion ( $\mathrm{T}$ factor), lymph node metastasis ( $\mathrm{N}$ factor) and distant metastases (M factor) (Table 1).

Immunohistochemical staining. All tissue specimens were fixed in $10 \%$ buffered formalin solution, dehydrated and embedded in paraffin. Obtained paraffin blocks were cut on microtome into 5 $\mu \mathrm{m}$ thick sections. In order to visualize antigen the sections were heated in a microwave. Monoclonal mouse antibodies were used for detection of MMP-9 (Mouse monoclonal antibody, NCLMMP9-439, Novocastra; dilution 1:40). The antigen-antibody complex was visualized by means of DAB chromogen (Novocastra).

MMP-9 expression was localized in the cytoplasm of neoplastic and inflammatory cells, visualized as brown, fine granular deposits (Fig. 1).

Expression of MMP-9 in gastric cancer tissue was evaluated with light microscopy using semi-quantitative scale: $0 \mathrm{pt}-$ no reaction; $1 \mathrm{pt}$ - weak reaction; 2 pts - moderate reaction; 3 pts intense reaction. Intensity of the metalloproteinase 9 expression in the inflammatory infiltrate (macrophages, polinuclears, lymphocytes) were evaluated in the same score. The obtained data
Table 1. Characteristics of gastric cancer patients

\begin{tabular}{|l|l|c|}
\hline \multicolumn{2}{|c|}{ Variable } & No of patients \\
\hline Giastric cancer patients & l'emale & 54 \\
\cline { 2 - 3 } Gender & Male & 13 \\
\hline \multirow{4}{*}{ Age } & $<65$ years & 41 \\
\cline { 2 - 3 } & $\geq 65$ years & 22 \\
\cline { 2 - 3 } & Range & 32 \\
\hline \multirow{4}{*}{ Depth of tumor stage } & I+II & 14 \\
\cline { 2 - 3 } & III & 22 \\
\cline { 2 - 3 } & IV & 18 \\
\hline \multirow{3}{*}{ Lymph node metastases } & T2 & 11 \\
\cline { 2 - 3 } & I3 & 31 \\
\cline { 2 - 3 } & I'4 & 12 \\
\hline \multirow{2}{*}{ Distant metastascs } & N negative & 16 \\
\cline { 2 - 3 } & N positive & 38 \\
\hline & M0 & 42 \\
\cline { 2 - 3 } & Ml & 12 \\
\hline
\end{tabular}

are presented as a number of cases and percentages in each analysed subgroup.

\section{Results}

\section{Relationship between MMP-9 expression in neoplastic cells and the clinicopathological features of gastric cancer}

The expression of MMP-9 was observed in the cytoplasm of neoplastic cells as brown, fine granular deposits (Fig. 1). The semi-quantitive scale was used, from null $(0 \mathrm{pt})$ to intense reaction $(3 \mathrm{pts})$. The results of immunohistochemical testing for MMP-9 in gastric cancer cells are summarized in Table 2. A positive reaction of MMP-9 was evaluated in $98 \%$ of all gastric cancer tissue specimens. The expression of MMP-9 was weak in $22 \%$, moderate in $22 \%$ and intense in $54 \%$ of cases, while null reaction was observed in $2 \%$ of cancer tissues. MMP-9 immunoreactivity in neoplastic tissue was associated with clinicopathological features of gastric cancer (Table 2). If we consider the TNM stage, immunohistochemical testing revealed a positive reaction in nearly $100 \%$ of cases in all stages. However, there were more of intense reactions ( $3 \mathrm{pts}$ ) in subgroup IV (72\%) than in patients with early stages (I+II) $(21 \%)$ of disease.

Relationship between MMP-9 expression and depth of tumor invasion ( $\mathrm{T}$ factor) was analyzed in Table 2. A positive reaction of MMP-9 was observed in almost $100 \%$ of all subgroups. Additionally, in T4 subgroup there were more cases with intense reactions (3 pts) of MMP-9 (83\%) in comparison to T2 subgroup (36\%). 


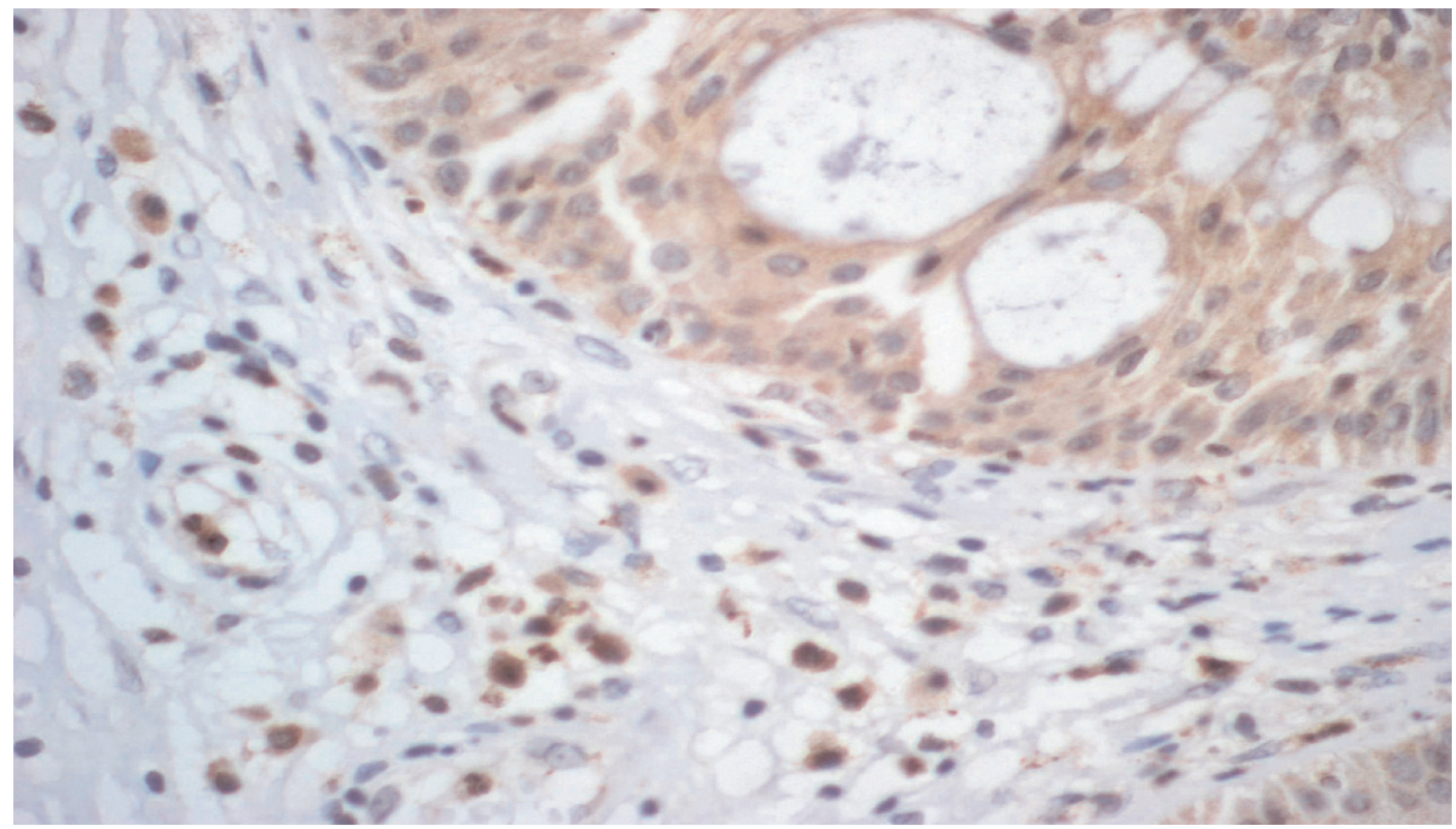

Fig. 1. Intense expression of MMP-9 in gastric cancer cells (3 pts) and moderate expression in inflammatory cells (2 pts).

Similar results were observed when we evaluated the MMP-9 immunoreactivity in tumor samples in comparison with lymph node metastases. The immunohistochemical staining revealed that the positive reaction of MMP-9 was observed in 94\%, whereas null reaction was evaluated in $6 \%$ of $\mathrm{N}$ negative subgroup. However, in $\mathrm{N}$ positive subgroups a positive expression was observed in $100 \%$ of cases. More intense reactions (3 pts) were evaluated in patients with lymph node invasion $(71 \%)$ than in those without nodal metastases $(13 \%)$. In addition, in $\mathrm{N}$ negative subgroup, the percentages of weak $(56 \%)$ MMP-9 expression was considerably higher in comparison to the patients with lymph node metastasis $(8 \%)$.

If we consider the distant metastases ( $\mathrm{M}$ factor), less weak reaction (1 pt) was observed in M0 (24\%) than in patients with distant metastases (M1) $(17 \%)$, while the percentages of positive, intense expression (3 pts) of MMP-9 was lower in M0 subgroup (52\%) versus M1 patients (58\%).

\section{Relationship between MMP-9 expression in inflammatory cells and the clinicopathological features of gastric cancer}

The expression of MMP-9 in inflammatory cells in relation to clinicopathological parameters of cancer was evaluated in Table 2. Among 54 gastric cancers patients, the incidence of a positive reaction was observed in $93 \%$ of tissue samples, with the strong immunoreactivity of MMP-9 in 70\%, weak and moderate expression in $11 \%$ of tumor samples, while negative reaction was observed in $7 \%$ of all cases.

High percentages of MMP-9 expression were demonstrated in the patients with advanced stages (III and IV) (100\%, 94\%, respectively) when compared to early cancer $(79 \%)$. Moreover, the MMP-9 expression was more intense ( 3 pts) in advanced tumor stage.

In relationship between MMP-9 expression in inflammatory cells and depth of tumor invasion, we observed less positive, intense (3 pts) reaction of MMP-9 staining in T2 subgroup (55\%) in comparison with T3 and T4 group (74\% and 75\%, respectively). Similarly, the percentage of weak expression was higher in samples from patients with T2 subgroup $(27 \%)$ versus patients with $\mathrm{T} 3$ and $\mathrm{T} 4$ group $(10 \%$, and $0 \%$, respectively).

There was no negative MMP-9 expression in patients with lymph node metastases (N-positive) in comparison with $\mathrm{N}$-negative subgroup (25\%). Moreover, the percentages of intense reactions ( $3 \mathrm{pts})$ were almost three-fold higher in patients with lymph node invasion $(87 \%)$ when compared with those without nodal metastases $(31 \%)$.

An association between MMP-9 immunoreactivity in inflammatory cells and distant metastases (M fac- 
able 2. The expression of matrix metalloproteinase-9 in relation to clinicopathological features of tumor.

\begin{tabular}{|c|c|c|c|c|c|c|c|c|c|c|c|c|}
\hline \multirow{3}{*}{\multicolumn{3}{|c|}{ Group tested }} & \multicolumn{5}{|c|}{$\begin{array}{l}\text { Expression of MMP-9 } \\
\text { in gastric cancer cells }\end{array}$} & \multicolumn{5}{|c|}{$\begin{array}{c}\text { Fxpression of MMP-9 } \\
\text { in interstitial inflammatory infiltrate cells }\end{array}$} \\
\hline & & & \multirow{2}{*}{ negative } & \multicolumn{4}{|c|}{ positive } & \multirow{2}{*}{ negative } & \multicolumn{4}{|c|}{ positive } \\
\hline & & & & + & ++ & +++ & all & & + & ++ & +++ & all \\
\hline \multirow{2}{*}{\multicolumn{2}{|c|}{ Gastric cancer patients $(n=54)$}} & Cases & 1 & 12 & 12 & 29 & 53 & 4 & 6 & 6 & 38 & 50 \\
\hline & & $\%$ & 2 & 22 & 22 & 54 & 98 & 7 & 11 & 11 & 70 & 93 \\
\hline \multirow{6}{*}{ TNM stage } & \multirow{2}{*}{$\mathrm{I}+\mathrm{II}(\mathrm{n}=14)$} & Cases & 0 & 8 & 3 & 3 & 14 & 3 & 5 & 1 & 5 & 11 \\
\hline & & $\%$ & 0 & 57 & 21 & 21 & 100 & 21 & 38 & 7 & 38 & 79 \\
\hline & \multirow{2}{*}{ III $(n=22)$} & Cases & 0 & 2 & 7 & 13 & 22 & 0 & 0 & 1 & 21 & 22 \\
\hline & & $\%$ & 0 & 9 & 32 & 59 & 100 & 0 & 0 & 5 & 95 & 100 \\
\hline & \multirow{2}{*}{ IV $(n=18)$} & Cases & 1 & 2 & 2 & 13 & 17 & 1 & 1 & 4 & 12 & 17 \\
\hline & & $\%$ & 28 & 11 & 11 & 72 & 94 & 28 & 28 & 22 & 67 & 94 \\
\hline \multirow{6}{*}{$\begin{array}{l}\text { Depth of tumor } \\
\text { invasion }\end{array}$} & \multirow{2}{*}{$12(n=11)$} & Cases & 0 & 4 & 3 & 4 & 11 & 1 & 3 & 1 & 6 & 10 \\
\hline & & $\%$ & 0 & 36 & 27 & 36 & 100 & 9 & 27 & 9 & 55 & 91 \\
\hline & \multirow{2}{*}{$\mathrm{T} 3(\mathrm{n}=31)$} & Cases & 1 & 7 & 8 & 15 & 30 & 2 & 3 & 3 & 23 & 29 \\
\hline & & $\%$ & 3 & 23 & 26 & 48 & 97 & 6 & 10 & 10 & 74 & 93 \\
\hline & \multirow{2}{*}{$\mathrm{T} 4(\mathrm{n}=12)$} & Cases & 0 & 1 & 1 & 10 & 12 & 1 & 0 & 2 & 9 & 11 \\
\hline & & $\%$ & 0 & 8 & 8 & 83 & 100 & 8 & 0 & 17 & 75 & 92 \\
\hline \multirow{4}{*}{$\begin{array}{l}\text { Lymph node } \\
\text { metastases }\end{array}$} & \multirow{2}{*}{$\begin{array}{l}N \text { negative } \\
(\mathrm{n}=16)\end{array}$} & Cases & 1 & 9 & 4 & 2 & 15 & 4 & 6 & 1 & 5 & 12 \\
\hline & & $\%$ & 6 & 56 & 25 & 13 & 94 & 25 & 38 & 6 & 31 & 75 \\
\hline & \multirow{2}{*}{$\begin{array}{l}N \\
(n=38)\end{array}$} & Cases & 0 & 3 & 8 & 27 & 38 & 0 & 0 & 5 & 33 & 38 \\
\hline & & $\%$ & 0 & 8 & 21 & 71 & 100 & 0 & 0 & 13 & 87 & 100 \\
\hline \multirow{4}{*}{$\begin{array}{l}\text { Distant } \\
\text { metastases }\end{array}$} & \multirow{2}{*}{$\mathrm{M} 0(\mathrm{n}=42)$} & Cases & 0 & 10 & 10 & 22 & 42 & 3 & 5 & 3 & 31 & 39 \\
\hline & & $\%$ & 0 & 24 & 24 & 52 & 100 & 7 & 12 & 7 & 74 & 93 \\
\hline & \multirow{2}{*}{$\mathrm{Ml}(\mathrm{n}=12)$} & Cases & 1 & 2 & 2 & 7 & 11 & 1 & 1 & 3 & 7 & 11 \\
\hline & & $\%$ & 8 & 17 & 17 & 58 & 92 & 8 & 8 & 25 & 58 & 92 \\
\hline
\end{tabular}

tor) was also demonstrated. A total positive reaction of MMP-9 was similar in patients with distant metastases (M1) and in M0 subgroup. However, in patients without distant metastases the percentages of weak MMP9 immunoreactivity (12\%) was higher than in M1 subgroup (8\%).

\section{Discussion}

MMPs are a group of enzymes responsible for degradation of extracellular matrix (ECM). Among the MMPs, MMP-9 plays very important role in cancer metastasis, because of their ability to degrade type IV collagen, a main component of vascular basement membrane, physical barrier for cells migrating in tissue $[8,23]$.

In the present study immunohistochemical staining was used to demonstarate the immunoreactivity of MMP-9 protein. The expression of this enzyme in neoplastic and interstitial inflammatory infiltrate cells from gastric cancer patients was evaluated. The intensity of the MMP-9 expression was presented using a semi-quantitative scale.

Immunohistochemical testing revealed that positive reaction of MMP-9 was observed in 98\% of all neoplastic cells, while null expression only in $2 \%$ of tissue samples. Several authors have also proved high expression of MMP-9 in gastric cancer tissue [10$12,14,15]$, although, according to our knowledge, there have been no studies assessing the MMP-9 expression in the interstitial inflammatory infiltrate cells in GC tissues. In the present paper the immunoreactivity of MMP-9 in inflammatory cells was evaluated. The positive reaction in inflammatory cells was observed in $93 \%$ of tissues samples, while the intense expression in $70 \%$ of cases.

Clinicopathological features of gastric cancer, such as TNM stage, the depth of tumor invasion, lymph node and distant metastases were analyzed according to the MMP-9 expression in tumor tissue. The strong 
immunoreactivity of MMP-9 increased in advanced tumors $(72 \%)$ when compared with early stage of cancer $(21 \%)$. Our findings are in accordance with other studies $[8,14]$, indicating that in early stages of $\mathrm{GC}$ the overexpression of this protein has been found in $34 \%$ of cases, whereas in advanced stages $-100 \%$. Moreover, the intense expression of this enzyme was increased with depth of tumor invasion ( $\mathrm{T}$ factor) and in patients with lymph node and distant metastases. Our observation was in the line with other authors $[8,10,14,15]$. Several studies have demonstrated strong correlation between MMP-9 expression and presence of lymph node metastases $[10,14]$. In addition, Gao et al [15] proved that the expression of MMP-9 and collagen type IV in the patients with metastasis were significantly higher than those without metastasis.

In the current study, the intensity of MMP-9 expression in inflammatory cells increased with more advance tumor stage, depth of tumor invasion and lymph node metastases. Tan et al [13] have shown that expression of MMP-9 was not detected in 30 cases of normal gastric mucosa, while weakly positive staining was observed in 63 cases of peri-tumor tissue. Some clinical investigation have proved that leukocytes infiltration can promote angiogenesis, growth and invasion of tumor $[24,25]$. This may be a result of cytokines, growth factors, chemokines and proteases secretion by inflammatory cells as well as stimulation of proliferation and enhancing the invasiveness of cancer cells $[19,26]$. Moreover, it was suggested that overexpression of MMPs on tumor infiltrating lymphocytes (TIL) within cancer tissue might be a result of host response induced by neoplastic cells and thus plays an important role in gastric cancer invasion and metastases [16].

Our results suggest that overexpression of MMP-9 in neoplastic and inflammatory cells in GC plays an important role in the progress of this carcinoma. In the present study, the synthesis of this enzyme by neoplastic cells as well as by inflammatory infiltrate cells of gastric cancer was demonstrated. We also observed the association between MMP-9 immunoreactivity and clinicopathological features of gastric cancer, such as TNM stage, the depth of tumor invasion, lymph node and distant metastases. In conclusion, MMP-9 may be used as a marker for invasiveness and metastasis of gastric cancer, however these findings still needs to be further investigated.

\section{References}

[ 1] Brenner H, Rothenbacher D, Arndt V. Epidemiology of stomach cancer. Methods Mol Biol. 2009;472:467-477.

[2] Samson PS, Escovidal LA, Yrastorza SG, Veneracion RG, Nerves MY. Re-study of gastric cancer: analysis of outcome. World J Surg. 2002;26:428-433.
[3] Shim KN, Jung SA, Joo YH, Yoo K. Clinical significance of tissue levels of matrix metalloproteinases and tissue inhibitors of metalloproteinases in gastric cancer. $J$ Gastroenterol. 2007; 42:120-128.

[4] Schwartz GK. Invasion and metastases in gastric cancer: in vitro and in vivo models with clinical correlations. Semin Oncol. 1996;23:316-324.

[ 5] Wagenaar-Miller RA, Gorden L, Matrisian LM. Matrix metalloproteinases in colorectal cancer: is it worth talking about? Cancer Metastasis Rev. 2004;23:119-135.

[6] Lebensztejn DM, Skiba E, Sobaniec-Łotowska ME, Kaczmarski M. Matrix metalloproteinases and their tissue inhibitors in children with chronic hepatitis B treated with lamivudine. Adv Med Sci. 2007;52:114-119.

[7] Nabeshima K, Inoue T, Shimao Y et al. Matrix metalloproteinases in tumor invasion: Role for cell migration. Pathol International. 2002;52:255-264.

[ 8] Kabashima A, Maehara Y, Kakeji Y, Baba H, Koga T, Sugimachi K. Clinicopathological features and overexpression of matrix metalloproteinases in intramucosal gastric carcinoma with lymph node metastasis. Clin Cancer Res. 2000;6:35813584.

[ 9] Yasumitsu H, Miyazaki K, Umenishi F, Koshikawa N, Umeda M. Comparison of extracellular matrix-degrading activities between $64-\mathrm{kDa}$ and $90-\mathrm{kDa}$ gelatinases purified in inhibitorfree forms from human schwannoma cells. J Biochem. 1992; 111:74-80

[10] Czyzewska J, Guzińska-Ustymowicz K, Kemona A, Bandurski R. The expression of matrix metalloproteinase 9 and cathepsin B in gastric carcinoma is associated with lymph node metastasis, but not with postoperative survival. Folia Histochem Cytobiol. 2008;46:57-64.

[11] De Mingo M, Morán A, Sánchez-Pernaute A et al. Expression of MMP-9 and TIMP-1 as prognostic markers in gastric carcinoma. Hepatogastroenterology. 2007;54:315-319.

[12] Seo YS, Park JJ, Kim JH et al. Usefulness of MMP-9/TIMP1 in predicting tumor recurrence in patients undergoing curative surgical resection for gastric carcinoma. Dig Dis Sci. 2007:52:753-759

[13] Tan SY, Wang JY, Shen L, Luo HS, Shen ZX. Relationship between preoperative staging by endoscopic ultrasonography and MMP-9 expression in gastric carcinoma. World J Gastroenterol. 2007;13:2108-2112.

[14] Zhang S, Li L, Lin JY, Lin H. Imbalance between expression of matrix metalloproteinase-9 and tissue inhibitor of metalloproteinase- 1 in invasiveness and metastasis of human gastric carcinoma. World J Gastroenterol. 2003;9:899-904.

[15] Gao ZL, Zhang C, Du GY, Lu ZJ. Clinical significance of changes in tumor markers, extracellular matrix, MMP-9 and VEGF in patients with gastric carcinoma. Hepatogastroenterology. 2007;54:1591-1595.

[16] Koyama S. Enhanced cell surface expression of matrix metalloproteinases and their inhibitors, and tumor-induced host response in progression of human gastric carcinoma. Dig Dis Sci. 2004;49:1621-1630.

[17] Liotta LA, Kohn EC. The microenvironment of the tumorhost interface. Nature. 2001;411:375-379.

[18] Bhowmick NA, Neilson EG, Moses HL. Stromal fibroblasts in cancer initiation and progression. Nature. 2004;432:332-337.

[19] Gonzalez LO, Pidal I, Junquera S et al. Overexpression of matrix metalloproteinases and their inhibitors in mononuclear inflammatory cells in breast cancer correlates with metastasis-relapse. Br J Cancer. 2007;97:957-963.

[20] Yoshikawa T, Tsuburaya A, Kobayashi O et al. Prognostic value of tissue inhibitor of matrix metalloproteinase-1 in plasma of patients with gastric cancer. Cancer Lett. 2000;151:81-86.

[21] Mroczko B, Kozłowski M, Groblewska M et al. Expression of matrix metalloproteinase- 9 in the neoplastic and interstitial 
inflammatory infiltrate cells in the different histopathological types of esophageal cancer. Folia Histochem Cytobiol. 2008; 46:471-478.

[22] Sobin LH, Wittenkind C. International Union Against Cancer (UICC) TNM classification of malignant tumours, $5^{\text {th }}$ edition. New York: Willey-Liss. 1997.

[23] Seiki M, Yana I. Roles of pericellular proteolysis by membrane type-1 matrix metalloproteinase in cancer invasion and angiogenesis. Cancer Sci. 2003;94:569-574.

[24] Coussens LM, Werb Z. Inflammation and cancer. Nature. 2002;420:860-867.
[25] Daniel D, Chiu C, Giraudo E et al. CD4+ T cell-mediated antigen-specific immunotherapy in a mouse model of cervical cancer. Cancer Res. 2005;65:2018-2025.

[26] Nelson AR, Fingleton B, Rothenberg ML, Matrisian LM. Matrix metalloproteinases: biologic activity and clinical implications. J Clin Oncol. 2000;18:1135-49.

Submitted: 21 April, 2009 Accepted after reviews: 18 August, 2009 